\title{
LPS from $P$. gingivalis Negatively Alters Gingival Cell Mitochondrial Bioenergetics
}

\author{
Kiran Napa, ${ }^{1}$ Andrea C. Baeder, ${ }^{1}$ Jeffrey E. Witt, ${ }^{2}$ Sarah T. Rayburn, ${ }^{1}$ Madison G. Miller, \\ Blake W. Dallon, ${ }^{2}$ Jonathan L. Gibbs, ${ }^{2}$ Shalene H. Wilcox, ${ }^{1}$ Duane R. Winden, ${ }^{1}$ \\ Jared H. Smith, ${ }^{2}$ Paul R. Reynolds, ${ }^{2}$ and Benjamin T. Bikman ${ }^{2}$ \\ ${ }^{1}$ College of Dental Medicine, Roseman University of Health Sciences, South Jordan, UT, USA \\ ${ }^{2}$ Department of Physiology and Developmental Biology, Brigham Young University, Provo, UT 84602, USA
}

Correspondence should be addressed to Benjamin T. Bikman; benjamin_bikman@byu.edu

Received 23 November 2016; Revised 13 February 2017; Accepted 20 March 2017; Published 16 May 2017

Academic Editor: Gianrico Spagnuolo

Copyright (C) 2017 Kiran Napa et al. This is an open access article distributed under the Creative Commons Attribution License, which permits unrestricted use, distribution, and reproduction in any medium, provided the original work is properly cited.

Objective. Oral inflammatory pathologies are linked to increased oxidative stress, thereby partly explaining their relevance in the etiology of systemic disorders. The purpose of this work was to determine the degree to which LPS from Porphyromonas gingivalis, the primary pathogen related to oral inflammation, altered gingival mitochondrial function and reactive oxygen species generation. Methods. Human gingival fibroblast (HGF-1) cells were treated with lipopolysaccharide of $P$. gingivalis. Mitochondrial function was determined via high-resolution respirometry. Results. LPS-treated HGF-1 cells had significantly higher mitochondrial complex IV and higher rates of mitochondrial respiration. However, this failed to translate into greater ATP production, as ATP production was paradoxically diminished with LPS treatment. Nevertheless, production of the reactive $\mathrm{H}_{2} \mathrm{O}_{2}$ was elevated with LPS treatment. Conclusions. LPS elicits an increase in gingival cell mitochondria content, with a subsequent increase in reactive oxygen species production (i.e., $\mathrm{H}_{2} \mathrm{O}_{2}$ ), despite a paradoxical reduction in ATP generation. These findings provide an insight into the nature of oxidative stress in oral inflammatory pathologies.

\section{Introduction}

In the United States, one out of every two American adults over the age of 30 has periodontal disease [1]. Periodontal disease manifests in two forms: gingivitis and periodontitis. While gingivitis is the inflammation of the gingival tissue, without the loss of supporting tooth structure, periodontitis, the more severe form of periodontal disease, is an infectious disease characterized by inflammation within the supporting tissues of the teeth with progressive attachment and bone loss [2]. Chronic periodontitis is the most common form of periodontitis, initiated and sustained by the presence of microorganisms, the innate immune response, and a variety of genetic factors [3].

Understandably, the primary focus for periodontal disease is the oral cavity, though its consequences extend systemically, including insulin resistance [4], diabetes $[4,5]$, arthritis [6], and heart disease [7]. Research efforts have largely focused on inflammation as the major mediating mechanism between periodontitis and systemic complications [8]. However, in addition to inflammation, alterations in mitochondrial function leading to oxidative stress have also been implicated in mediating both oral and systemic pathologies [9-11], though this paradigm requires further exploration.

Like other cells, oral gingiva is highly responsive to the bacterial endotoxin, lipopolysaccharide (LPS), which is prevalent in periodontal disease [12]. Indeed, LPS may be responsible for the inflammation and oxidative stress that accompany the periodontal disease. Considering the relevance of oxidative stress in a myriad of oral and systemic pathologies, we sought to better understand the concise consequences of LPS on gingival cell mitochondrial bioenergetics. 


\section{Methods}

2.1. Cell Culture. Human gingival fibroblast (HGF-1) cells were maintained in Dulbecco's modified Eagle's medium (DMEM) plus 15\% fetal bovine serum (FBS) and $2 \%$ $\mathrm{Pen} /$ Strep at $37^{\circ} \mathrm{C}$. The culture medium was replaced twice a week until the cells reached $80 \%$ confluency. The cells were rinsed with phosphate-buffered saline (PBS), trypsinized, and split into $6-10 \mathrm{~mm}$ plates. The medium was replaced twice a week until the cells reached about $80 \%$ confluency. For LPS treatment, cells were treated with lipopolysaccharide of Porphyromonas gingivalis (LPS, $5 \mu \mathrm{g} / \mathrm{mL}$ ) for $48 \mathrm{~h}$.

2.2. Mitochondrial Respiration. Cells were prepared for mitochondrial respiration as described previously $[13,14]$ before being transferred to respirometer chambers using the Oroboros O2K oxygraph. Electron flow through complex I was supported by glutamate + malate (10 and $2 \mathrm{mM}$, resp.) to determine leak oxygen consumption $\left(\mathrm{GM}_{L}\right)$. Following stabilization, ADP (2.5 mM) was added to determine oxidative phosphorylation capacity $\left(\mathrm{GM}_{P}\right)$. Succinate was added $\left(\mathrm{GMS}_{P}\right)$ for complex I + II electron flow into the Q-junction. To determine full electron transport system capacity in cells over oxidative phosphorylation, the chemical uncoupler carbonyl cyanide 4-(trifluoromethoxy)phenylhydrazone (FCCP) was added $(0.05 \mu \mathrm{M}$, followed by $0.025 \mu \mathrm{M}$ steps until maximal $\mathrm{O}_{2}$ flux was reached; $\mathrm{GMS}_{F}$ ). Mitochondrial membrane integrity was tested in all experiments by adding cytochrome $c$ (not shown; $10 \mu \mathrm{M}$ ). Lastly, residual oxygen consumption was measured by adding antimycin $\mathrm{A}(2.5 \mu \mathrm{M})$ to block complex III action, effectively stopping any electron flow, which provides a baseline rate of respiration. Following the respiration protocol, samples were removed from the chambers and used for further analysis, including protein quantification. Respiratory control ratio (RCR) and uncoupling control ratio (UCR) were determined by the ratio of $\mathrm{GM}_{P}: \mathrm{GM}_{L}$ and $\mathrm{GMS}_{F}$ : GMS , respectively.

2.3. ATP Production. ATP production was determined using the Oroboros $\mathrm{O} 2 \mathrm{~K}$ oxygraph, as described previously [15]. Briefly, ATP production was determined after addition of ADP $(2.5 \mathrm{mM})$ by measuring changes in free extramitochondrial $\left[\mathrm{Mg}^{+}\right]$using Magnesium Green (MgG; Life Technologies). Fluorescence was measured with $503 \mathrm{~nm}$ and $530 \mathrm{~nm}$ excitation and emission, respectively.

2.4. $\mathrm{H}_{2} \mathrm{O}_{2}$ Production. An average rate of $\mathrm{H}_{2} \mathrm{O}_{2}$ generation was determined using the Oroboros $\mathrm{O} 2 \mathrm{~K}$ oxygraph. Amplex UltraRed $(5 \mu \mathrm{M}$; Thermo Fisher), horseradish peroxidase (1 U/mL; Sigma), and superoxide dismutase ( $5 \mathrm{U} / \mathrm{mL}$; Sigma) were added to the chambers prior to the addition of cells. Following addition of various substrates indicated above, $\mathrm{H}_{2} \mathrm{O}_{2}$ $(0.1 \mu \mathrm{M}$; Sigma $)$ was added as a calibration to determine endogenous $\mathrm{H}_{2} \mathrm{O}_{2}$ production.

2.5. Mitochondrial Morphology. HGF-1 cells were grown to confluence in chamber slides (NUNC Lab-Tek II Chambered Coverglass System; 155382). The mitochondrial dye
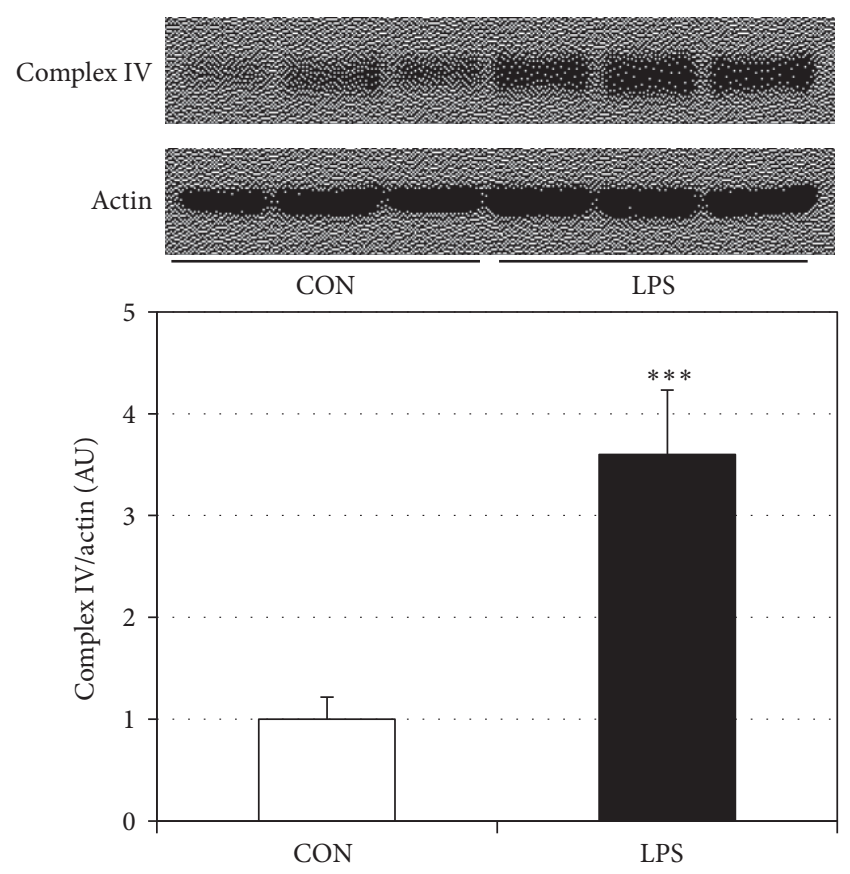

FIGURE 1: LPS increases complex IV protein expression in HGF-1 cells. Human gingival fibroblasts were treated with LPS $(5 \mu \mathrm{g} / \mathrm{mL})$ for $48 \mathrm{~h}$, after which complex IV protein levels were determined $(n=$ 4). ${ }^{* * *} P<0.001$.

MitoTracker Red CMXRos (Molecular Probes; M7512), dissolved in anhydrous dimethylsulfoxide (DMSO), was added to the culture at $250 \mathrm{nM}$. The cells were incubated for 30 minutes at $37^{\circ} \mathrm{C}$ in the dark and then visualized using a confocal microscope (Olympus IX81).

2.6. Statistical Methods. Data are presented as means \pm SEM. Data were compared with one-way ANOVA or Student's $t$ test (Graphpad Prism; Microsoft Excel). Significance was set at $P<0.05$.

\section{Results}

3.1. LPS Increases Mitochondrial Electron Transport Complex $I V$ and Respiration. Human gingival fibroblasts incubated with LPS from $P$. gingivalis had an over threefold increase in complex IV protein content (Figure 1), consistent with previous reports (Hansen et al., 2015). Moreover, independent of the protein amount, LPS-treated cells had significantly increased respiration rates at each step of the respiration protocol (Figure 2(a)). However, minimal differences were noted between respiration rates in the LPS-treated cells in the leak state $\left(G_{L}\right)$ and ADP addition $\left(G_{P}\right)$ and succinate addition $\left(\mathrm{GMS}_{P}\right)$ and FCCP uncoupler $\left(\mathrm{GMS}_{F}\right)$, respectively. When comparing post hoc analyses of mitochondrial respiration, we found that LPS-treated gingival cells experienced a reduction in the respiratory control ratio (Figure 2(b)), a rough indication of mitochondrial health, and the uncoupling control ratio was decreased in LPS-treated gingival cells compared to control (Figure 2(c)). 


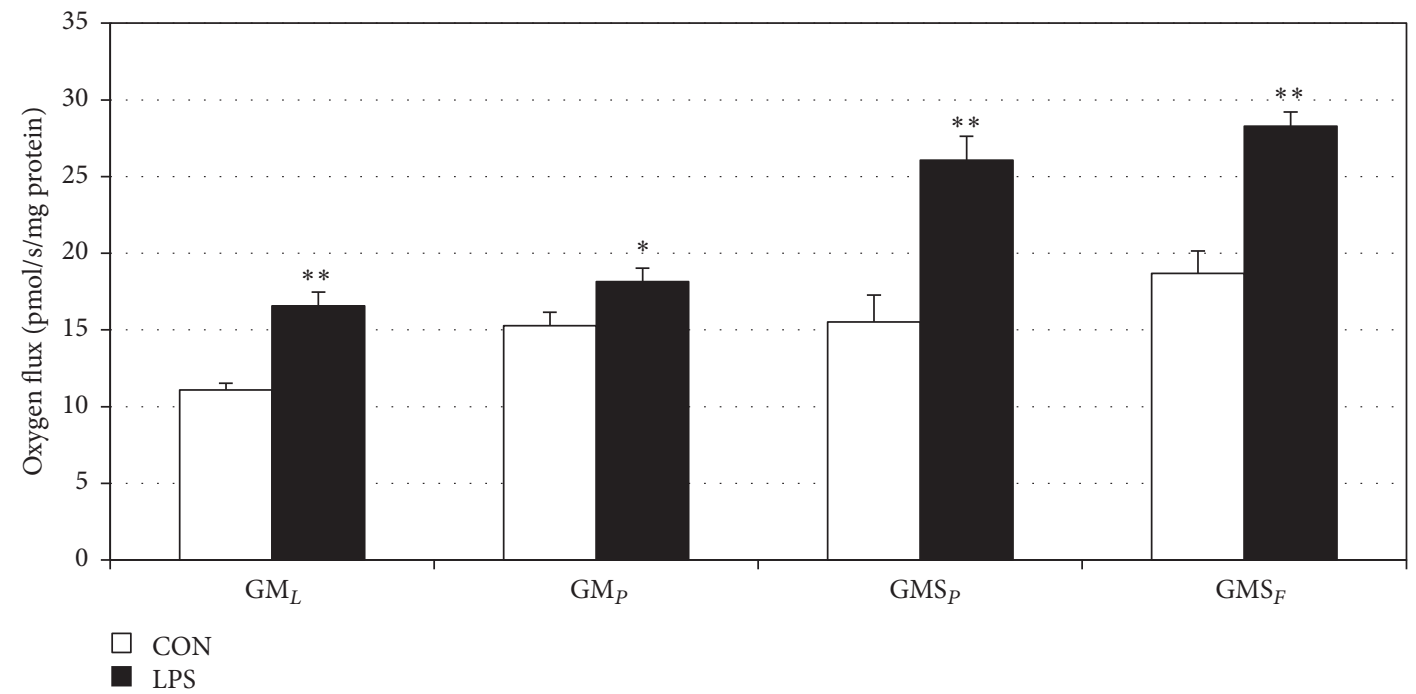

(a)

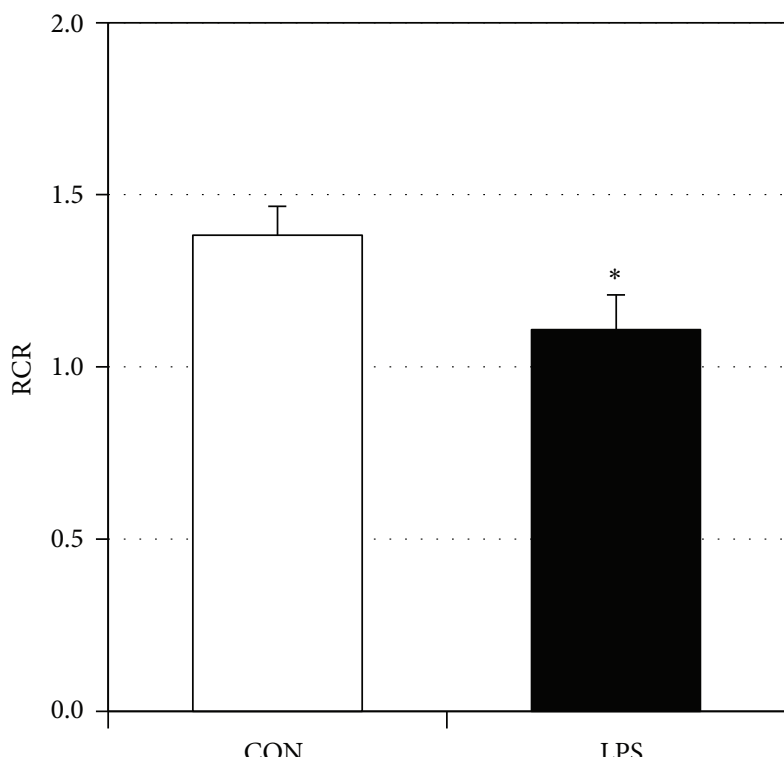

(b)

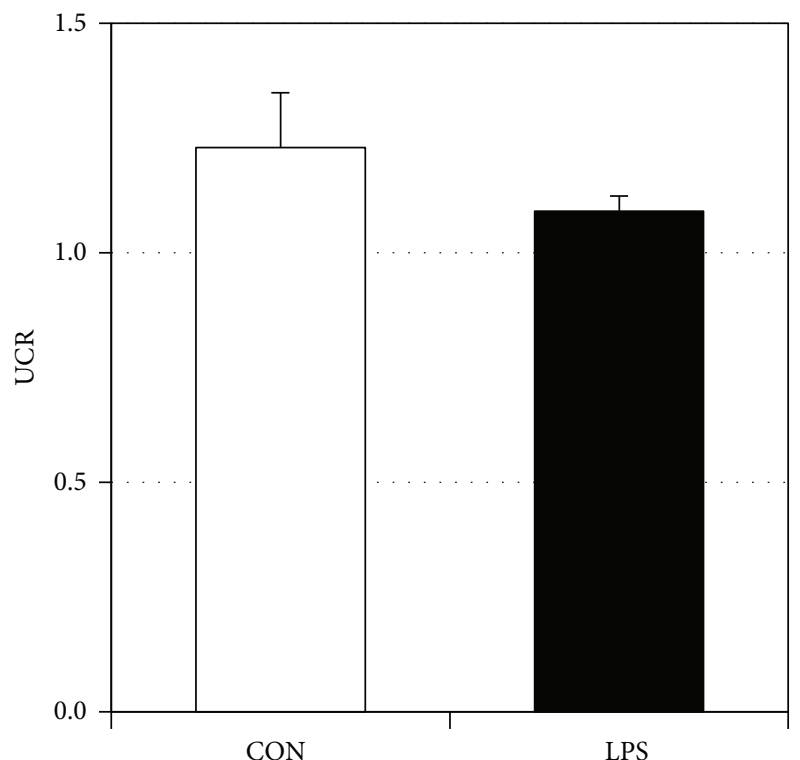

(c)

FIGURE 2: LPS alters HGF-1 mitochondrial bioenergetics. Mitochondrial assessments were determined in permeabilized (digitonin, $1 \mathrm{mg} / \mathrm{mL}$ ) HGF-1 cells following treatment with LPS $(5 \mu \mathrm{g} / \mathrm{mL})$ for $48 \mathrm{~h}$. To measure mitochondrial respiration (a), samples were sequentially treated with $\mathrm{GM}_{L}$ (glutamate $(10 \mathrm{mM})+$ malate $\left.(2 \mathrm{mM})\right), \mathrm{GMP}_{P}$ (glutamate $\left.(10 \mathrm{mM})+\mathrm{ADP}(2.5 \mathrm{mM})\right), \mathrm{GMS}_{P}$ (glutamate $(10 \mathrm{mM})+$ succinate $(10 \mathrm{mM}))$, and $\mathrm{GMS}_{F}$ (glutamate $\left.(10 \mathrm{mM})+\mathrm{FCCP}(0.05 \mu \mathrm{M})\right)$. Respiratory control ratio (RCR, (b)) and uncoupling control ratio (UCR, (c)) were determined by the analysis indicated in the Methods $(n=4) .{ }^{*} P<0.05 ;{ }^{* *} P<0.01$.

3.2. LPS Decreases ATP Production and Increases $\mathrm{H}_{2} \mathrm{O}_{2}$ Production. In addition to general respiration, we analyzed specific use of oxygen by measuring ATP production and $\mathrm{H}_{2} \mathrm{O}_{2}$ generation. LPS-treated gingival fibroblasts had a significant reduction in ATP production (Figure 3(a)). Moreover, the ratio of peak ATP production to oxygen consumption decreased in the LPS-treated gingival cells compared to control (Figure 3(b)), suggesting a deleterious change in mitochondrial physiology. Lastly, $\mathrm{H}_{2} \mathrm{O}_{2}$ production from LPS-treated gingival fibroblasts was significantly higher than in control (Figure 4), indicating increased oxidative stress.
3.3. LPS Increases Gingival Cell Mitochondrial Fission. We have previously found that LPS forces sustained mitochondrial fission in muscle cells and that fission is a key event in disrupting mitochondrial physiology $[16,17]$. We found that the same series of events occurs in gingival cells. In particular, we observed a significant increase in protein levels of dynamin-related protein 1 (DRP1) following LPS treatment (Figure 5(a)). DRP1 is a key regulator of mitochondrial fission. This finding was substantiated by visualizing a greater degree of segmented and distinct mitochondria following LPS treatment (Figure 5(b)). 


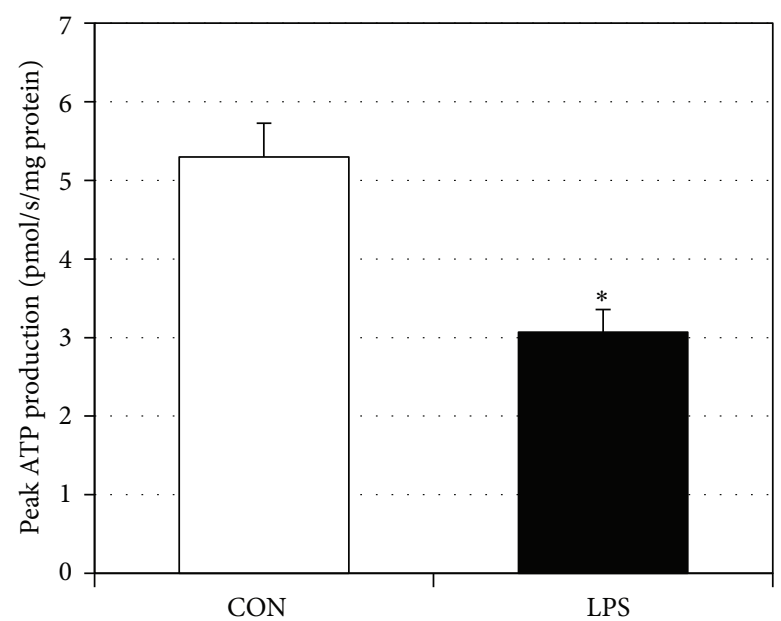

(a)

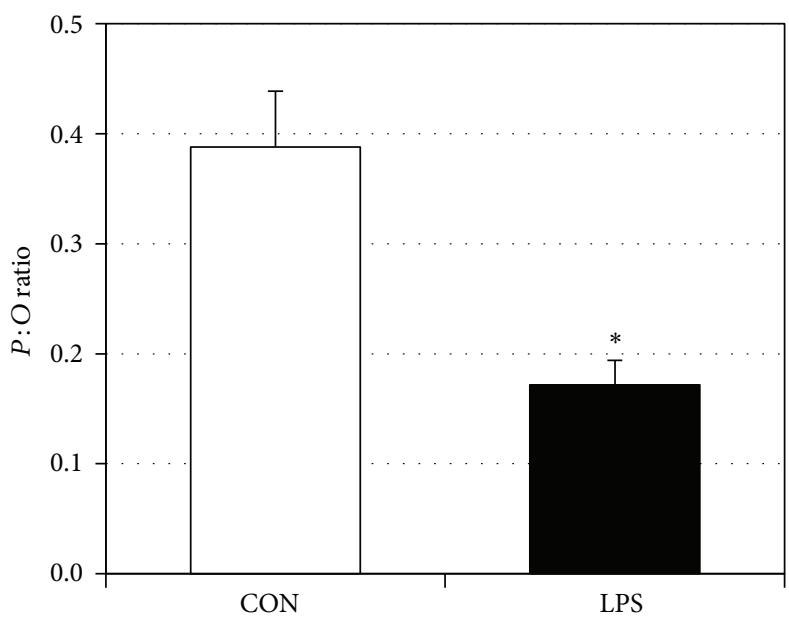

(b)

Figure 3: LPS reduces ATP production in HGF-1 cells. To determine ATP production following LPS treatment ((a), $5 \mu \mathrm{g} / \mathrm{mL}$ for $48 \mathrm{~h})$, Magnesium Green fluorescence $(503 / 530 \mathrm{nM})$ was determined during respiration after calibration with ADP $(2.5 \mathrm{mM})(n=3)$. The rate of peak ATP production was then compared against the rate of oxygen consumption to determine the $\mathrm{P}: \mathrm{O}$ ratio $((\mathrm{b}), n=3) .{ }^{*} P<0.05$.

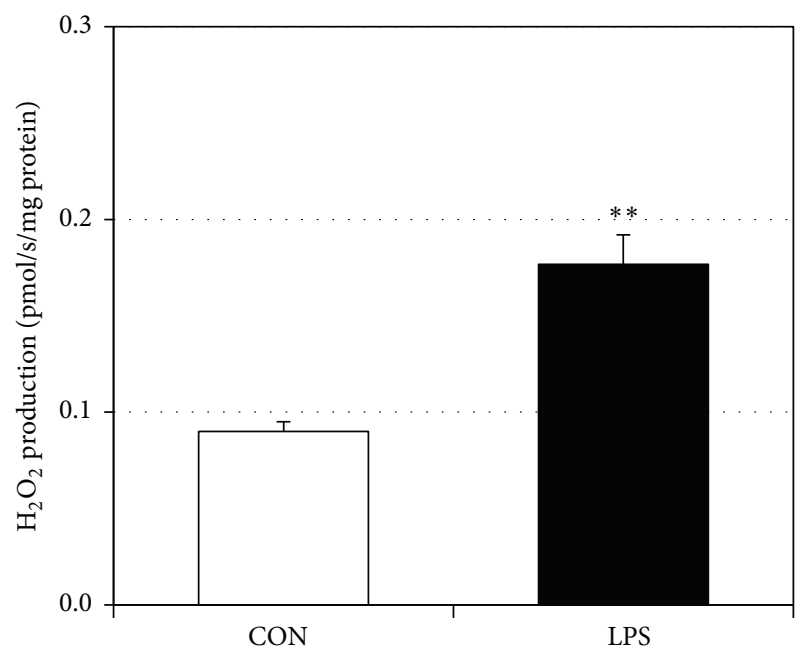

Figure 4: LPS increases $\mathrm{H}_{2} \mathrm{O}_{2}$ production in HGF-1 cells. To determine $\mathrm{H}_{2} \mathrm{O}_{2}$ production following LPS treatment ((a), $5 \mu \mathrm{g} / \mathrm{mL}$ for $48 \mathrm{~h}$ ), Amplex UltraRed fluorescence (530/590 nM) was determined during respiration after calibration with $\mathrm{H}_{2} \mathrm{O}_{2}(0.1 \mu \mathrm{M}, n=3)$. ${ }^{* *} P<0.01$.

\section{Discussion}

The oral cavity contains a remarkable number of diverse bacteria. Of this substantial cohort, roughly 400 are thought to predominate during periodontal infections [18]; and of this group, a substantial portion contain lipopolysaccharides (LPS) in the cell wall. LPS is a powerful ligand that activates multiple immune-related receptors and, not surprisingly, has potent immune-activating effects on white blood cells, including macrophages and lymphocytes. In addition to classically promoting cytokine production, LPS also alters mitochondrial function in these cells [19]. However, the full extent to which LPS alters gingival mitochondrial function remains unclear.

The purpose of these studies was to better understand the pathology of gingival disease, with particular emphasis on the altered mitochondrial bioenergetics in the presence of LPS. We found that LPS elicited potent pathogenic changes in gingival cell mitochondrial function. Importantly, for the first time, we found that gingival cell LPS treatment yielded a significant increase in mitochondrial respiration while reducing ATP production and increasing $\mathrm{H}_{2} \mathrm{O}_{2}$ generation. These two changes in particular, namely, reduced ATP generation and increased $\mathrm{H}_{2} \mathrm{O}_{2}$ production, represent fundamental changes in mitochondrial homeostasis that would readily yield decayed cellular function. Furthermore, these changes may arise from the LPS-induced alteration in mitochondrial morphology, namely, forced mitochondrial fission, likely via increased DRP1 expression. Importantly, these are highly novel findings that, when considered in combination, allow a greater appreciation of the extent of gingival cell mitochondrial changes with LPS exposure. For example, Bullon et al. [20] found increased reactive oxygen species (ROS) production in gingival cells after LPS treatment, despite overall reduced mitochondrial function. However, there was no measurement of ATP.

Collectively, our data contribute to a growing paradigm regarding the nature of the pathogenic mitochondrial changes that occur in gingival cells with increased LPS exposure. The combination of a reduction in ATP generation and enhanced $\mathrm{H}_{2} \mathrm{O}_{2}$ production reveals an interesting shift in oxygen use. While oxygen consumption was increased with LPS treatment, it is evident that, rather than being appropriately used to facilitate ATP production via the electron transport system, which is necessary to maintain cellular homeostasis, oxygen is rather contributing to the formation of reactive oxygen species. 

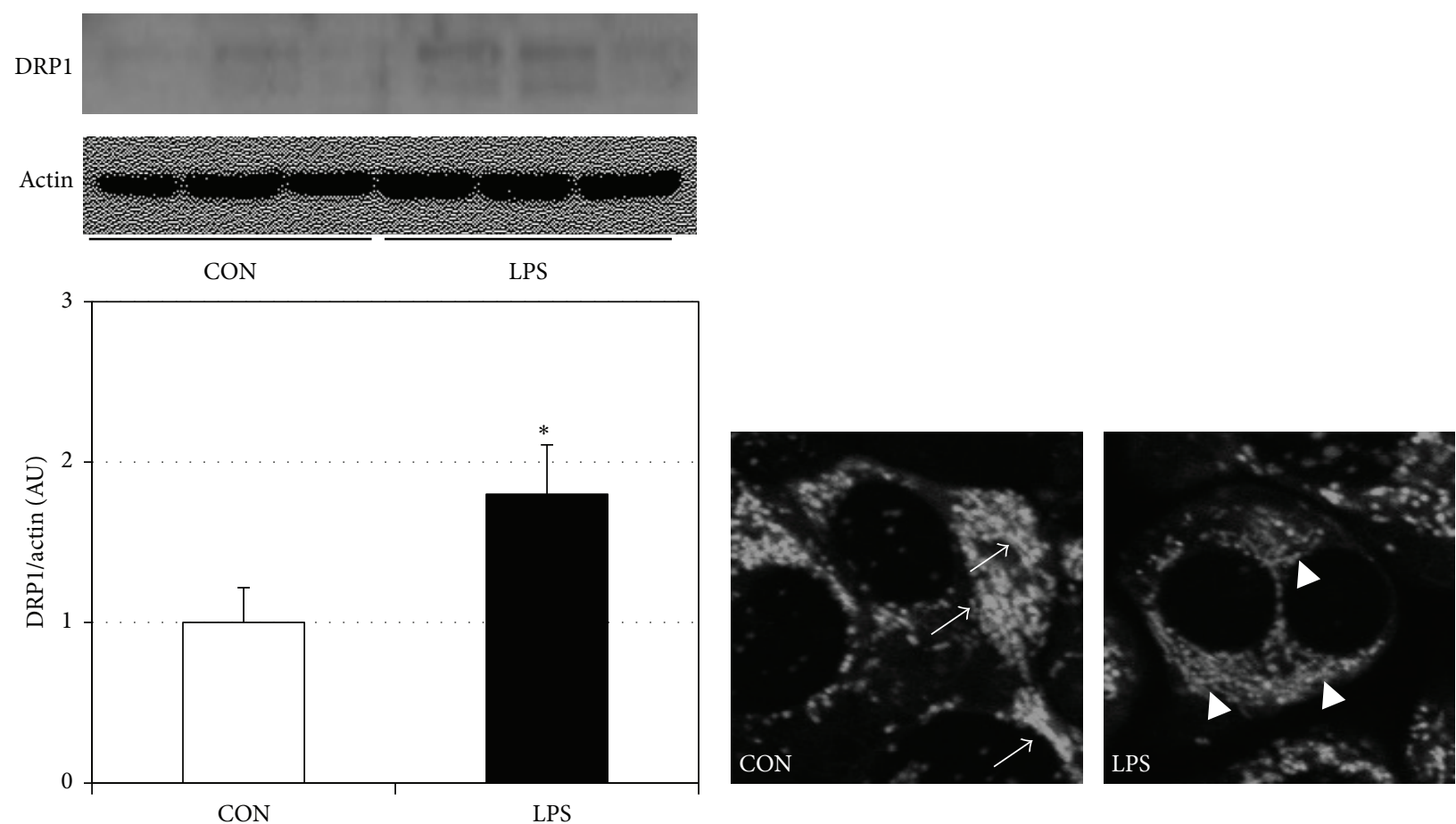

(a)

(b)

FIGURE 5: LPS increases mitochondrial fission in HGF-1 cells. Following LPS treatment $(5 \mu \mathrm{g} / \mathrm{mL}$ for $48 \mathrm{~h})$, cells were either harvested to determine DRP1 levels via western blot $((\mathrm{a}), n=4)$ or visualized via confocal microscopy ((b); white arrows indicate sections of fusion; white arrowheads indicate fission; $n=3) .{ }^{*} P<0.05$ for CON versus LPS.

Importantly, the relevance of increased ROS generation arising from gingival inflammation extends well beyond the oral cavity. While certainly relevant in oral pathologies, including destruction of oral cells [21], the oxidative stress arising from increased LPS exposure to gingival cells may play a role in multiple systemic disorders. In particular, the ROS spread into the general circulation and increase the risk of cardiovascular disorders [22, 23], stroke [24], insulin resistance [25], and even pregnancy complications [26].

In conclusion, these studies reveal multiple novel findings regarding the mitochondrial response within gingival cells to LPS from $P$. gingivalis. Overall rate of mitochondrial respiration is increased, despite an atypical and significant reduction in ATP generation. Rather than being used to produce ATP, the increased respiration appears to be increasing the production of harmful $\mathrm{H}_{2} \mathrm{O}_{2}$, which may drive oral and systemic pathologies. Altogether, these data suggest a potential role for antioxidant therapies in helping mitigate the consequences of orally derived oxidative stress.

\section{Disclosure}

Kiran Napa and Andrea C. Baeder are co-first authors.

\section{Conflicts of Interest}

The authors declare that they have no conflicts of interest regarding the publication of this paper.

\section{Authors' Contributions}

Kiran Napa, Andrea C. Baeder, Sarah T. Rayburn, and Benjamin T. Bikman conceived the project. Kiran Napa, Andrea C. Baeder, Jeffrey E. Witt, Sarah T. Rayburn, Madison G. Miller, Blake W. Dallon, Jonathan L. Gibbs, Jared H. Smith, and Benjamin T. Bikman performed all experiments. Shalene H. Wilcox, Duane R. Winden, and Paul R. Reynolds assisted by providing intellectual direction and data analysis.

\section{Acknowledgments}

Benjamin T. Bikman is supported by the Kevin and Mimi Sayer Diabetes Research Endowment at Brigham Young University and a Bobbitt Heart Disease Award. Paul R. Reynolds is supported by the Flight Attendant's Medical Research Institute (FAMRI).

\section{References}

[1] P. I. Eke, B. A. Dye, L. Wei et al., "Update on prevalence of periodontitis in adults in the United States: NHANES 2009 to 2012," Journal of Periodontology, vol. 86, no. 5, pp. 611-622, 2015.

[2] J. Lindhe, R. Ranney, I. Lamster et al., "Consensus report: chronic periodontitis," Annals of Periodontology, vol. 4, no. 1, pp. 38-38, 1999.

[3] “The pathogenesis of periodontal diseases," Journal of Periodontology, vol. 70, no. 4, pp. 457-470, 1999. 
[4] G. W. Taylor, B. A. Burt, M. P. Becker et al., "Severe periodontitis and risk for poor glycemic control in patients with non-insulindependent diabetes mellitus," Journal of Periodontology, vol. 67, no. 10s, pp. 1085-1093, 1996.

[5] B. Chee, B. Park, and P. M. Bartold, "Periodontitis and type II diabetes: a two-way relationship," International Journal of Evidence-Based Healthcare, vol. 11, no. 4, pp. 317-329, 2013.

[6] N. R. Fuggle, T. O. Smith, A. Kaul, and N. Sofat, "Hand to mouth: a systematic review and meta-analysis of the association between rheumatoid arthritis and periodontitis," Frontiers in Immunology, vol. 7, article 80, 2016.

[7] J. D. Beck, S. Offenbacher, R. Williams, P. Gibbs, and R. Garcia, "Periodontitis: a risk factor for coronary heart disease?" Annals of Periodontology, vol. 3, no. 1, pp. 127-141, 1998.

[8] B. G. Loos, "Systemic markers of inflammation in periodontitis," Journal of Periodontology, vol. 76, no. 11-s, pp. 2106-2115, 2005.

[9] F. D’Aiuto, L. Nibali, M. Parkar, K. Patel, J. Suvan, and N. Donos, "Oxidative stress, systemic inflammation, and severe periodontitis," Journal of Dental Research, vol. 89, no. 11, pp. 1241-1246, 2010.

[10] I. Borges Jr., E. A. Machado Moreira, D. W. Filho, T. B. de Oliveira, M. B. S. da Silva, and T. S. Fröde, "Proinflammatory and oxidative stress markers in patients with periodontal disease," Mediators of Inflammation, vol. 2007, Article ID 45794, 5 pages, 2007.

[11] A. L. Horton, K. A. Boggess, K. L. Moss, J. Beck, and S. Offenbacher, "Periodontal disease, oxidative stress, and risk for preeclampsia," Journal of Periodontology, vol. 81, no. 2, pp. 199204, 2010.

[12] T. Ara, K. Kurata, K. Hirai et al., "Human gingival fibroblasts are critical in sustaining inflammation in periodontal disease," Journal of Periodontal Research, vol. 44, no. 1, pp. 21-27, 2009.

[13] T. S. Tippetts, D. R. Winden, A. C. Swensen et al., "Cigarette smoke increases cardiomyocyte ceramide accumulation and inhibits mitochondrial respiration," BMC Cardiovascular Disorders, vol. 14, no. 1, article 165, 2014.

[14] M. O. Thatcher, T. S. Tippetts, M. B. Nelson et al., "Ceramides mediate cigarette smoke-induced metabolic disruption in mice," The American Journal of Physiology-Endocrinology and Metabolism, vol. 307, no. 10, pp. E919-E927, 2014.

[15] A. Power, N. Pearson, T. Pham, C. Cheung, A. Phillips, and A. Hickey, "Uncoupling of oxidative phosphorylation and ATP synthase reversal within the hyperthermic heart," Physiological Reports, vol. 2, no. 9, 2014.

[16] M. E. Smith, T. S. Tippetts, E. S. Brassfield et al., "Mitochondrial fission mediates ceramide-induced metabolic disruption in skeletal muscle," Biochemical Journal, vol. 456, no. 3, pp. 427439, 2013.

[17] M. E. Hansen, K. J. Simmons, T. S. Tippetts et al., "Lipopolysaccharide disrupts mitochondrial physiology in skeletal muscle via disparate effects on sphingolipid metabolism," Shock, vol. 44, no. 6, pp. 585-592, 2015.

[18] B. J. Paster, I. Olsen, J. A. Aas, and F. E. Dewhirst, "The breadth of bacterial diversity in the human periodontal pocket and other oral sites," Periodontology 2000, vol. 42, no. 1, pp. 80-87, 2006.

[19] M. Wilson, "Biological activities of lipopolysaccharides from oral bacteria and their relevance to the pathogenesis of chronic periodontitis," Science Progress, vol. 78, no. Pt 1, pp. 19-34, 1995.

[20] P. Bullon, M. D. Cordero, J. L. Quiles, J. M. Morillo, M. D. C. Ramirez-Tortosa, and M. Battino, "Mitochondrial dysfunction promoted by porphyromonas gingivalis lipopolysaccharide as a possible link between cardiovascular disease and periodontitis," Free Radical Biology and Medicine, vol. 50, no. 10, pp. 1336-1343, 2011.

[21] R. Cheng, D. Choudhury, C. Liu, S. Billet, T. Hu, and N. A. Bhowmick, "Gingival fibroblasts resist apoptosis in response to oxidative stress in a model of periodontal diseases," Cell Death Discovery, vol. 1, p. 15046, 2015.

[22] P. Bullon, H. N. Newman, and M. Battino, "Obesity, diabetes mellitus, atherosclerosis and chronic periodontitis: a shared pathology via oxidative stress and mitochondrial dysfunction?" Periodontology 2000, vol. 64, no. 1, pp. 139-153, 2014.

[23] J. Beck, R. Garcia, G. Heiss, P. S. Vokonas, and S. Offenbacher, "Periodontal disease and cardiovascular disease," Journal of Periodontology, vol. 67, no. 10s, pp. 1123-1137, 1996.

[24] F. A. Scannapieco, R. B. Bush, and S. Paju, "Associations between periodontal disease and risk for atherosclerosis, cardiovascular disease, and stroke. a systematic review," Annals of Periodontology, vol. 8, no. 1, pp. 38-53, 2003.

[25] M. Shlossman, W. C. Knowler, D. J. Pettitt, and R. J. Genco, "Type 2 diabetes mellitus and periodontal disease," The Journal of the American Dental Association, vol. 121, no. 4, pp. 532-536, 1990.

[26] S. Offenbacher, H. L. Jared, P. G. O'Reilly et al., "Potential pathogenic mechanisms of periodontitis associated pregnancy complications," Annals of Periodontology, vol. 3, no. 1, pp. 233250, 1998. 


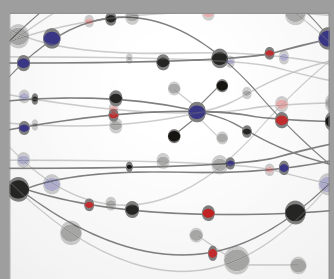

The Scientific World Journal
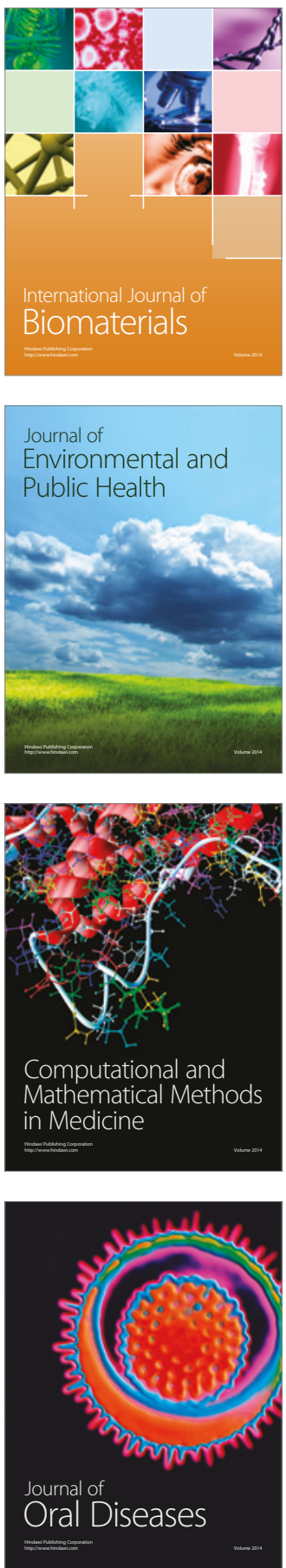
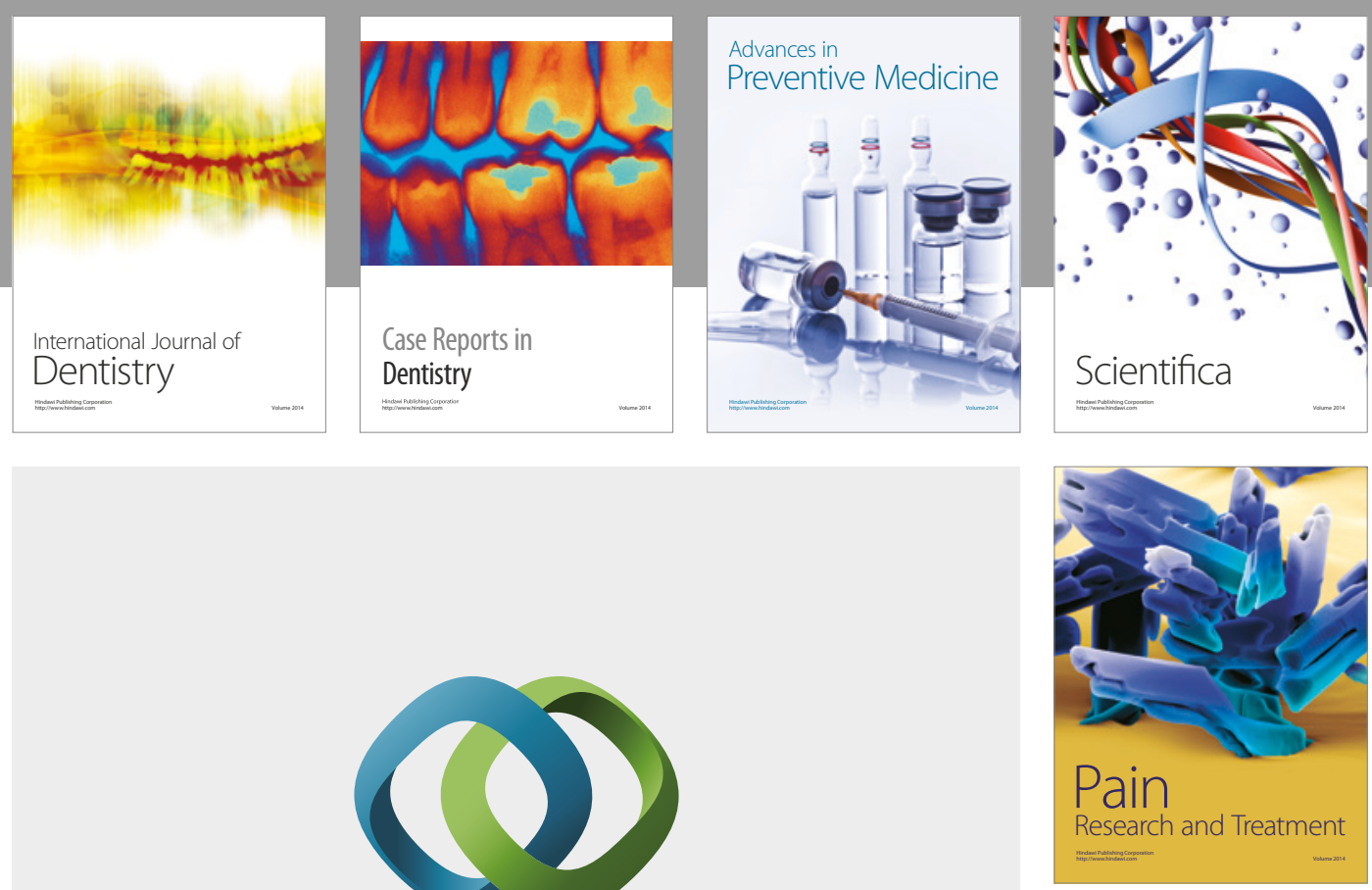

\section{Hindawi}

Submit your manuscripts at

https://www.hindawi.com
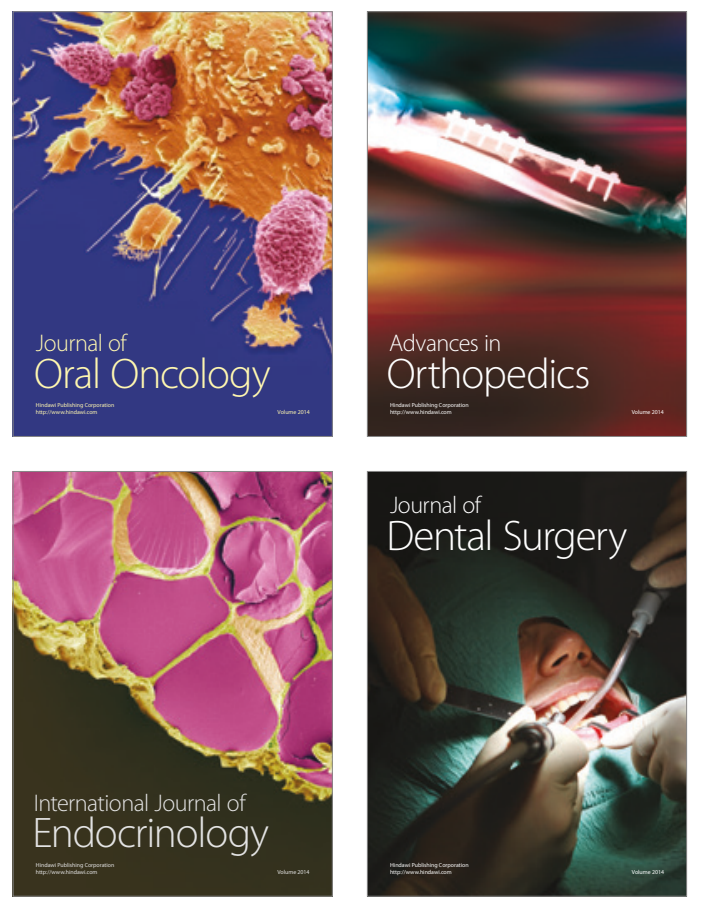
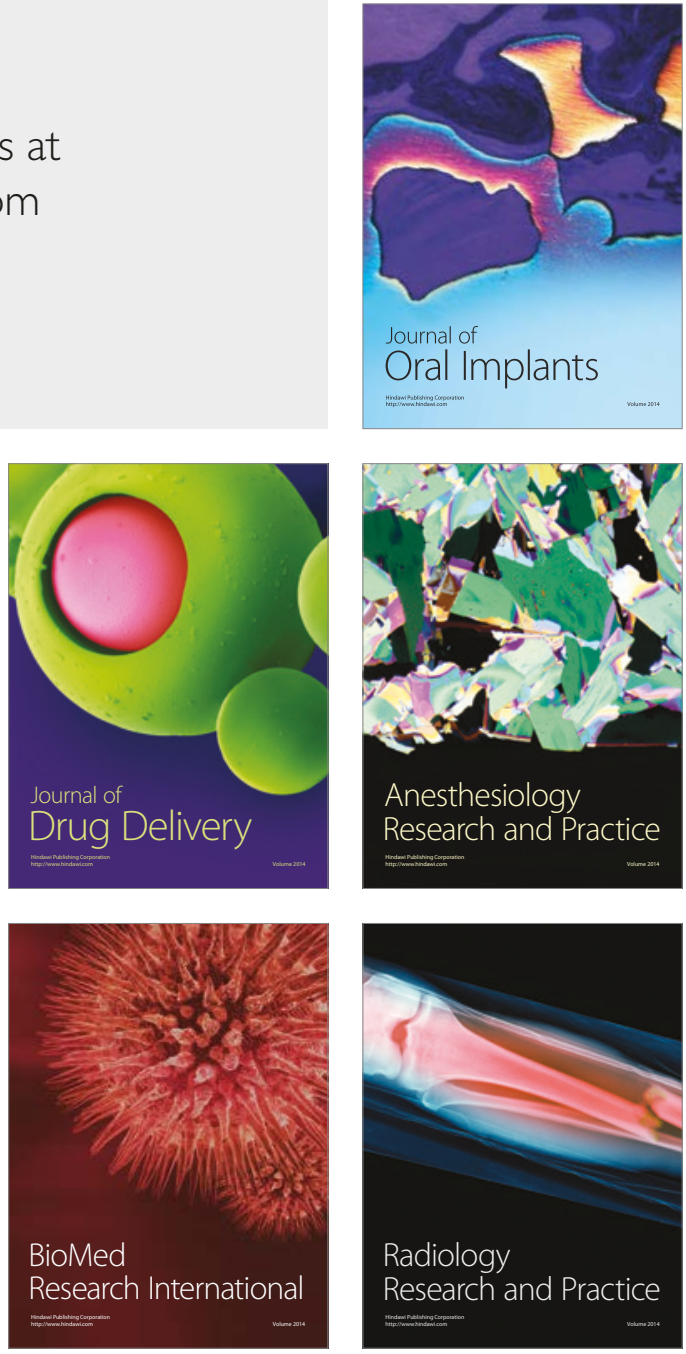